\title{
Cathodic reductive coupling of methyl cinnamate on boron-doped diamond electrodes and synthesis of new neolignan-type products
}

\author{
Taiki Kojima1 ${ }^{1}$, Rika Obata ${ }^{2}$, Tsuyoshi Saito ${ }^{3,4}$, Yasuaki Einaga ${ }^{* 1,4}$ \\ and Shigeru Nishiyama*1,4
}

\section{Letter}

\section{Address:}

${ }^{1}$ Department of Chemistry, Faculty of Science and Technology, Keio University, Hiyoshi 3-14-1 Kohoku-ku, Yokohama 223-8522, Japan,

${ }^{2}$ Research and Education Center for Natural Sciences, Keio University, Hiyoshi 4-1-1 Kohoku-ku, Yokohama 223-8521, Japan,

3 International Institute for Integrative Sleep Medicine, University of

Tsukuba, 1-1-1 Tennodai, Tsukuba, Ibaraki 305-8577, Japan and

${ }^{4}$ Japan Science and Technology Agency (JST), CREST, Hiyoshi

3-14-1, Yokohama 223-8522, Japan

\section{Email:}

Yasuaki Einaga* - einaga@chem.keio.ac.jp; Shigeru Nishiyama* -

nisiyama@chem.keio.ac.jp

* Corresponding author

Keywords:

boron-doped diamond (BDD) electrode; cathodic reduction;

electrochemistry; electrosynthesis; neolignan

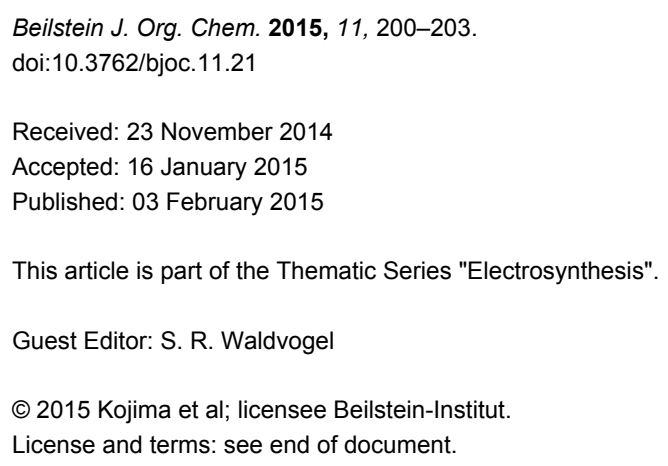

\begin{abstract}
The electroreduction reaction of methyl cinnamate on a boron-doped diamond (BDD) electrode was investigated. The hydrodimer, dimethyl 3,4-diphenylhexanedioate (racemate/meso $=74: 26$ ), was obtained in $85 \%$ yield as the major product, along with small amounts of cyclic methyl 5-oxo-2,3-diphenylcyclopentane-1-carboxylate. Two new neolignan-type products were synthesized from the hydrodimer.
\end{abstract}

\section{Introduction}

Numerous lignans and neolignans were found as secondary plant metabolites, and many of them are known to exhibit interesting biological activities [1]. Due to their plausible roles as defense substances of plants, lignans, neolignans, and their congeners are promising candidates for agricultural chemicals, and some of their antioxidant and/or anti-inflammatory prop- erties may be utilized for biological research and as lead structures for chemotherapeutic agents. Despite consisting of two phenylpropane $\left(\mathrm{C}_{6}-\mathrm{C}_{3}\right)$ fragments, the variety of carbon frameworks provides a huge library of lignans and neolignans [2-4]. As a result of their structural diversity, they have been targets of synthetic and biological investigations. Several synthetic 
approaches, including electrochemical oxidative coupling reactions mimicking biosynthetic pathways, were reported to construct the backbones of these molecules [5]. Recently, boron-doped diamond (BDD) electrodes have attracted a great deal of attention for their wide potential window against evolution of both hydrogen and oxygen and for their high stability which is derived from their diamond carbon structure [6]. Although anodic oxidation reactions mediated by BDD electrodes have been exploited in organic synthesis, there have been only few reports regarding their application in preparative-scale cathodic reduction of organic compounds [7].

During our investigations of phenolic oxidation reactions using BDD electrodes, we observed the generation of solvent-derived methoxy radicals that conducted an oxidation process of the phenol substrate to the corresponding coupling product [8]. In our second investigation on the use of the BDD electrode in organic synthesis, the electrochemical reduction of methyl cinnamate (1a) was investigated to assess the applicability of BDD electrodes under cathodic reduction conditions, and to obtain new neolignan-type bioactive substances. As shown in Figure 1, the radical intermediate derived from phenylacrylate through a one-electron reduction (right) differs from that obtained by anodic oxidation of 4-hydroxyphenyl-1-propene (left). Therefore, the reductive dimerization of cinnamic acid derivatives was expected to provide access to unprecedented neolignan-type dimeric compounds.

\section{Results and Discussion \\ Cathodic reduction on BDD electrode}

The ester methyl cinnamate (1a) was electrolyzed under constant current electrolysis (CCE) conditions in a divided cell. Solvents used for the reactions played a significant role in providing the desired coupling (Table 1, entries 1-5). Thus, only acetonitrile (Table 1, entry 5) gave the desired coupling product $( \pm)-2$ [9] in 4\% yield, recovered educt $1 \mathbf{a}$ and hydrolyzed product $\mathbf{1 b}$. The undesired hydrolysis could be depressed using a phosphate-buffered solution in the cathodic cell ( $\mathrm{pH} 7$, Table 1, entries 7-11), and finally the optimized conditions for the synthesis of $\mathbf{2}(85 \%$ yield, racemate $/$ meso $=$ $74: 26$ ) were acquired in the case of $2.5 \mathrm{~F} / \mathrm{mol}$ current (Table 1 , entry 11).

To check for a different behavior of the BDD electrode, several electrode materials, including glassy carbon (GC), platinum $(\mathrm{Pt})$, and magnesium $(\mathrm{Mg})$, were examined as cathodes under the optimized electrolytic conditions (Table 1, entry 11). Hydrogen evolution at the electrode was recognized when Pt and $\mathrm{Mg}$ electrodes were used, and the educt $\mathbf{1 a}$ was recovered in high yield. The GC electrode provided the coupling product 2 (34\%, racemate/meso $=74: 26)$ and $E-3(25 \%)$, along with $41 \%$ of 1a. Similar cathodic reductions of cinnamate derivatives were carried out using $\mathrm{Hg}$ [10,11], $\mathrm{Cu}$ [12,13], $\mathrm{Pb}$ [13,14], $\mathrm{Zn}$ [13], Sn [13], and $\mathrm{Ag}$ [13], and the major products were the cyclic products (type 3 ) through Diekmann-type cyclization, whereas the hydrodimer 2 was the predominantly produced product in the present BDD electrode mediated reduction. Despite a different product ratio, the GC electrode gave similar reaction products to that of the BDD electrode.

\section{Synthesis of new neolignans}

As shown in Scheme 1, after separation of the diastereomeric mixture, $( \pm)-2$ was submitted to the chemical conversion into the new neolignan-type derivatives $E-5$ and $E-8$. Thus, reduction of $( \pm)-2$ with $\mathrm{LiAlH}_{4}$ gave the alcohol $( \pm)-4$ [15] in quantitative yield, which on oxidation with PCC [16] gave the lactone $E-5$ in $32 \%$ yield. Selective DIBAL reduction of $E-5$ gave an inseparable mixture of 6 and 7, which were identified by ${ }^{1} \mathrm{H}$ NMR spectroscopy. Subsequent treatment of the mixture with $\mathrm{Et}_{3} \mathrm{SiH}$ in the presence of $\mathrm{BF}_{3} \cdot \mathrm{OEt}_{2}$ finally gave $E-\mathbf{8}$.

\section{Conclusion}

The cathodic reduction of $\mathbf{1}$ a using BDD electrode predominantly gave the dimeric product 2 in $85 \%$ yield. A<smiles>C/C=C/c1ccc(O)cc1/C=C/C(C)=CC(C)C(C)C=C1C=CC(=O)C=C1</smiles>

Reduction

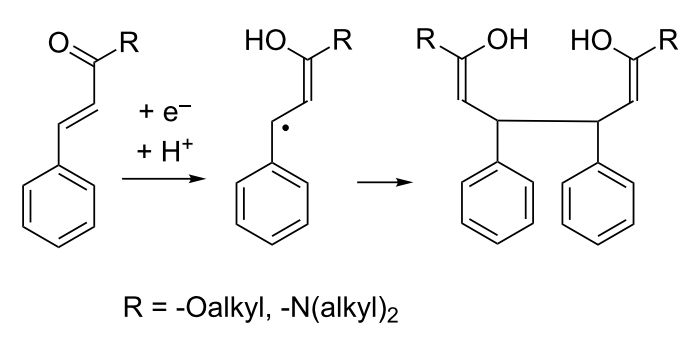

Figure 1: Expected coupling products from one-electron oxidation (left) and one-electron reduction (right) of $\mathrm{C}_{6}-\mathrm{C}_{3}$ compounds. 
Table 1: Cathodic reduction of 1a on a BDD electrode.

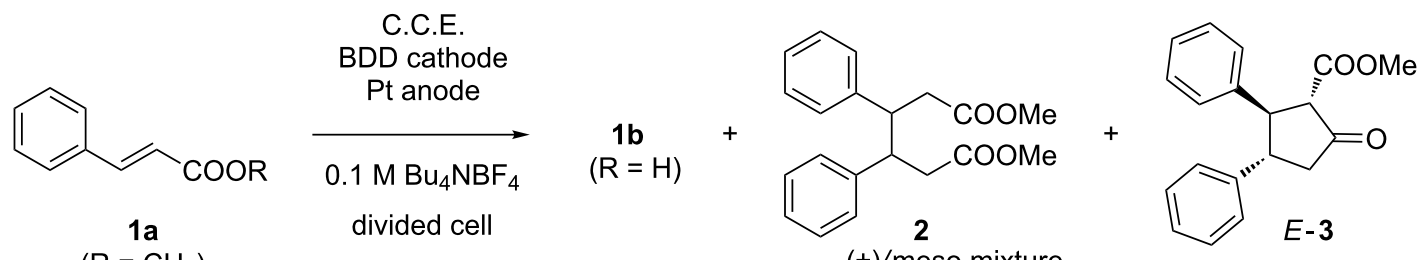

$\left(\mathrm{R}=\mathrm{CH}_{3}\right)$

$( \pm) /$ meso mixture

\begin{tabular}{|c|c|c|c|c|c|c|c|c|}
\hline \multirow[t]{2}{*}{ Entrya } & \multirow[t]{2}{*}{ Solvent } & \multirow{2}{*}{$\begin{array}{c}\text { Current } \\
\text { density }\left(\mathrm{mA} / \mathrm{cm}^{2}\right)\end{array}$} & \multirow{2}{*}{$\begin{array}{c}\text { Potential } \\
\text { (V vs SCE) }\end{array}$} & \multirow[t]{2}{*}{$\mathrm{F} / \mathrm{mol}$} & \multicolumn{4}{|c|}{ Yield $(\%)^{b}$} \\
\hline & & & & & $1 \mathrm{a}$ & $1 b$ & $2[( \pm) /$ meso $)]^{c}$ & $3^{d}$ \\
\hline 1 & DMSO & 0.21 & -2.08 to -1.93 & 1 & 32 & 51 & 0 & 0 \\
\hline 2 & DMF & 0.50 & -1.96 to -1.86 & 1 & 43 & 43 & 0 & 0 \\
\hline 3 & TFE $^{e}$ & 0.53 & -2.00 to -1.85 & 1 & 100 & 0 & 0 & 0 \\
\hline 4 & $\mathrm{MeOH}$ & 1.29 & -2.08 to -1.84 & 1 & 74 & 12 & 0 & 0 \\
\hline 5 & $\mathrm{MeCN}$ & 1.29 & -2.00 to -1.88 & 1 & 42 & 46 & $4(100 / 0)$ & 0 \\
\hline 6 & $\mathrm{MeCN}^{f}$ & 1.29 & -2.21 to -1.98 & 1 & 10 & 23 & $19(79 / 21)$ & 3 \\
\hline 7 & MeCNg & 1.29 & -2.07 to -1.89 & 1 & 23 & 13 & $33(85 / 15)$ & 5 \\
\hline 8 & $\mathrm{MeCN}^{\mathrm{h}}$ & 1.29 & -1.91 to -1.83 & 1 & 45 & 0 & $44(73 / 27)$ & 3 \\
\hline 9 & $\mathrm{MeCN}^{\mathrm{h}}$ & 1.29 & -2.02 to -1.84 & 1.5 & 26 & 0 & $67(73 / 27)$ & 5 \\
\hline 10 & $\mathrm{MeCN}^{\mathrm{h}}$ & 1.29 & -2.00 to -1.82 & 2.0 & 15 & 0 & $70(73 / 27)$ & 5 \\
\hline 11 & $\mathrm{MeCN}^{\mathrm{h}}$ & 1.29 & -2.12 to -1.93 & 2.5 & 1 & 0 & $85(74 / 26)$ & 4 \\
\hline
\end{tabular}

aUpon using undivided cell systems, the reaction proceeded slower than in the divided cell cases, and lower selectivity of 2 and $\mathbf{3}$ was observed. b Isolated yields. ${ }^{\mathrm{C}}$ The ratio of $( \pm)$ and meso forms was determined by ${ }^{1} \mathrm{H}$ NMR spectroscopy. ${ }^{\mathrm{d}}$ Enantiomeric mixture. ${ }^{\mathrm{e}} 2,2,2-\mathrm{Trifluoroethanol}$.

${ }^{\mathrm{f} C o n t a i n i n g} 0.07 \mathrm{M} \mathrm{pH} 6.0$ phosphate buffer. ${ }^{\mathrm{g}}$ Containing $0.07 \mathrm{M} \mathrm{pH} 7.0$ phosphate buffer. ${ }^{\mathrm{h}}$ Containing $0.33 \mathrm{M} \mathrm{pH} 7.0$ phosphate buffer.

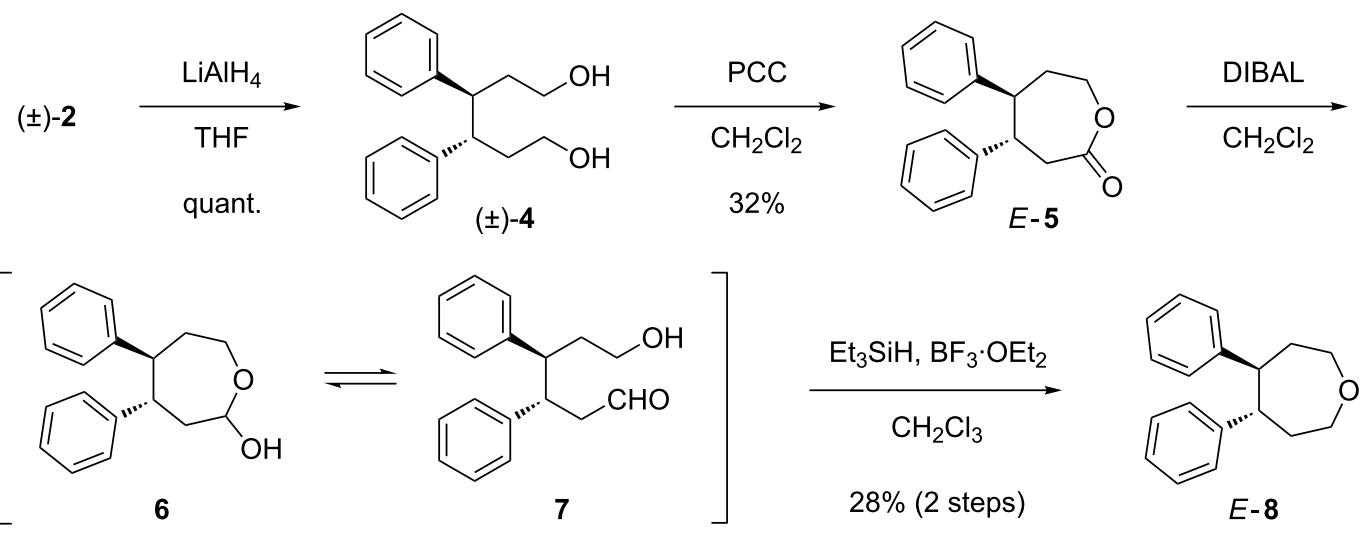

Scheme 1: Chemical conversion of ( \pm$)-2$ into $E-5$ and $E-8$.

remarkable solvent effect of $\mathrm{MeCN}$ was observed for this dimerization reaction, while stereoselectivity was unaffected among the conditions tested and the racemic form was predominant over the meso form in all cases. Electrochemically prepared $( \pm)-\mathbf{2}$ was further converted into $E-\mathbf{5}$ and $E-\mathbf{8}$ as novel unprecedented neolignan-type derivatives. These results provide an example for an electroorganic synthesis using cathodic reductive coupling on a boron-doped diamond electrode.

\section{Supporting Information}

\section{Supporting Information File 1}

Instrumental setup, general procedure for the electrochemical reaction and physical and spectroscopic data for ( \pm -2, meso-2, $E$-5, and $E-8$.

[http://www.beilstein-journals.org/bjoc/content/ supplementary/1860-5397-11-21-S1.pdf] 


\section{Acknowledgements}

This research was supported by grants from the Science Research Promotion Fund from the Promotion and Mutual Aid Corporation for Private Schools of Japan from MEXT, the Research and Education Center for Natural Sciences Keio University, and Keio Gijuku Academic Development Funds (to $\mathrm{RO})$.

\section{References}

1. Zhang, J.; Chen, J.; Liang, Z.; Zhao, C. Chem. Biodiversity 2014, 11, 1-54. doi:10.1002/cbdv.201100433

2. Apers, S.; Vlietinck, A.; Pieters, L. Phytochem. Rev. 2003, 2, 201-207. doi:10.1023/B:PHYT.0000045497.90158.d2

3. Ward, R. S. Nat. Prod. Rep. 1999, 16, 75-96. doi:10.1039/a705992b

4. Ward, R. S. Nat. Prod. Rep. 1997, 14, 43-74. doi:10.1039/np9971400043

5. Quideau, S.; Pouységu, L.; Duffieux, D. Curr. Org. Chem. 2004, 8, 113-148. doi:10.2174/1385272043486016 And related references cited therein.

6. Fuchigami, T.; Atobe, M.; Inagi, S. New Methodology of Organic Electrochemical Synthesis. In Fundamentals and Applications of Organic Electrochemistry: Synthesis, Materials, Devices; Fuchigami, T.; Atobe, M.; Inagi, S., Eds.; John Wiley \& Sons: Chichester, U.K., 2015; pp 129-186.

7. Waldvogel, S. R.; Mentizi, S.; Kirste, A. Top. Curr. Chem. 2012, 320, 1-31. doi:10.1007/128_2011_125

8. Sumi, T.; Saitoh, T.; Natsui, K.; Yamamoto, T.; Atobe, M.; Einaga, Y.; Nishiyama, S. Angew. Chem., Int. Ed. 2012, 51, 5443-5446. doi:10.1002/anie.201200878

9. Curtin, D. Y.; Dayagi, S. Can. J. Chem. 1964, 42, 867-877. doi:10.1139/v64-129 See for a separation of the ( \pm )-and meso-forms of 2

10. Klemm, L. H.; Olson, D. R. J. Org. Chem. 1973, 38, 3390-3394. doi:10.1021/j000959a034

11. Fussing, I.; Güllü, M.; Hammerich, O.; Hussain, A.; Nielsen, M. F.; Utley, J. H. P. J. Chem. Soc., Perkin Trans. 2 1996, 649-658. doi:10.1039/P29960000649

12. Nishiguchi, I.; Hirashima, T. Angew. Chem., Int. Ed. Engl. 1983, 22, 52-53. doi:10.1002/anie.198300521

13. Kise, N.; litaka, S.; Iwasaki, K.; Ueda, N. J. Org. Chem. 2002, 67, 8305-8315. doi:10.1021/jo026183k

14. Kise, N.; Echigo, M.; Shono, T. Tetrahedron Lett. 1994, 35, 1897-1900. doi:10.1016/S0040-4039(00)73190-X

15. Brook, A. G.; Cohen, H. L.; Wright, G. F. J. Org. Chem. 1953, 18, 447-463. doi:10.1021/jo01132a012

16. Ohgiya, T.; Nakamura, K.; Nishiyama, S. Bull. Chem. Soc. Jpn. 2005, 78, 1549-1554. doi:10.1246/bcsj.78.1549

\section{License and Terms}

This is an Open Access article under the terms of the Creative Commons Attribution License

(http://creativecommons.org/licenses/by/2.0), which permits unrestricted use, distribution, and reproduction in any medium, provided the original work is properly cited.

The license is subject to the Beilstein Journal of Organic Chemistry terms and conditions:

(http://www.beilstein-journals.org/bjoc)

The definitive version of this article is the electronic one which can be found at:

doi:10.3762/bjoc. 11.21 